\title{
Una mirada a la legislación y normativa vigente del género en Ecuador
}

\author{
Fanny Tubay Zambrano \\ ORCID: https://orcid.org/0000-0002-9156-0956 \\ fannytubay@hotmail.com \\ Universidad Técnica de Manabí \\ Portoviejo-Ecuador
}

\author{
María Angélica Henríquez \\ ORCID: https://orcid.org/0000-0003-2223-2470 \\ mariangelicahc@gmail.com \\ Universidad Técnica de Manabí \\ Portoviejo-Ecuador
}

\author{
Humberto Castillo Quintero \\ ORCID: http://orcid.org/0000-0001-5510-5780 \\ hpcastilloq@gmail.com \\ Universidad de los Andes \\ Mérida-Venezuela
}

Recibido (04/02/21), Aceptado (23/02/21)

\begin{abstract}
Resumen: Con el repaso de la normativa legal del género en el Ecuador, este trabajo muestra su estado actual y los avances desde una progresión teórica y práctica para construir un modelo de sociedad que tenga sus cimientos en la filosofía del buen vivir. A través de la metodología cualitativa, y del método documental se analizaron 13 instrumentos legales y 4 planes y proyectos estatales. Los resultados dan cuenta que a pesar de los importantes avances legislativos siguen existiendo falencias en materia de género en el país, pues en la práctica se requiere, por un lado, que el estado garantice el cumplimiento de la normativa, y que, por otro, que la sociedad en su conjunto la asuma responsablemente y lo haga posible.
\end{abstract}

Palabras Clave: Normativa legal, sociedad, género, derechos de la mujer

\section{A brief glance at the legislation and current regulations about gender in Ecuador}

Abstract: With a review of legal regulations of gender in Ecuador, this work shows its current status and the progress from a theoretical and practical progression to build a model of society based in the philosophy of good living. Through the qualitative methodology and the documentary method, 13 legal instruments and 4 state plans and projects were analyzed. The results show that despite the important legislative advances, there are still shortcomings in gender matters, since in practice it is required, on the one hand, that the state guarantee compliance with the regulations, and that, on the other, that society in its jointly assume it responsibly and make it possible.

Keywords: Legal regulations, Society, Gender, Women's Rights 


\section{I.INTRODUCCIÓN}

El género en las últimas décadas es un tema de interés y repercusión en las agendas globales, regionales y nacionales, dadas las circunstancias dispares y violentas por las que atraviesan muchas mujeres y otros colectivos con menor poder. Sin embargo, en contextos latino-americanos la ralentización de procesos que conlleva a nivel estructural, refleja una etapa de transición que no pasa del discurso a la práctica.

Para el caso de Ecuador, pese a que se trata de un asunto emergente y que forma parte de la política pública de orden prioritaria, los instrumentos legales diseñados a nivel estatal en los últimos diez años, no cobran la fuerza necesaria para trascender a las arenas sociales con los resultados esperados. De ahí que este estudio juzgue necesario hacer una revisión de la legislación de este país para conocer sus dimensiones y los modos como se articula y construye el corpus normativo de género.

La metodología utilizada en la investigación es la revisión documental que permitió hacer acopio del conjunto de leyes vigentes en la temática propuesta y aglutinar así las conquistas legales que respaldan el proceso de igualdad de género que viene aguardando el país.

Como producto de esta mirada result conveniente revisar los objetivos de desarrollo sostenible agendados para el 2030 por la ONU con el fin de ubicar la importancia temática de la investigación respecto a los intereses que el mundo está incentivando a conseguir. Posteriormente y ya contextualizados en Ecuador, se consultaron más de una docena de instrumentos legales de diversas jerarquías que forman parte de la estructura jurídica nacional. A la par se revisaron con el mismo rigor los planes, proyectos, sistemas y metodologías que permiten la praxis de esta legislación.

Acorde a los estudios de género las evidentes diferencias e injusticias que históricamente caracterizan las condiciones de vida de mujeres en diferentes ámbitos (familia, educación, política, laboral) mantienen en pie de lucha a los movimientos sociales, principalmente feministas, para exigir a las naciones y organismos internacionales tomar decisiones a favor de mejores condiciones y soluciones justas a problemáticas dispares [1].

La historia del feminismo y los hechos de cambio que se suscitaron en América Latina desde hace más de tres siglos han influido en las transformaciones sociales de la región. Y Ecuador desde esa postura ha desempeñado un papel importante, liderando y siendo ejemplo para otras naciones. Así encontramos algunos eventos históricos como el levantamiento de las mujeres indias y las cacicas contra la pretensión de nueva numeración de indios en 1777. Posteriormente, más de un siglo des- pués, Matilde Hidalgo protagonizó un hito histórico al ser la primera mujer en terminar la enseñanza secundaria en 1913, este mismo personaje prosiguió rompiendo moldes de su época logrando graduarse de médica en 1921, luego de una larga batalla jurídica en la universidad, logró condecorarse como la primera mujer que pudo sufragar en 1929, una vez que se aprobara la ley que otorga el sufragio a las mujeres. Dichos acontecimientos allanaron el camino y motivaron a otras féminas a luchar por cambios sustanciales en la sociedad conservadora ecuatoriana, tal es el caso de Carmela Suárez Veintimilla de López, quien en 1957 se convirtió en la primera mujer ecuatoriana que llegó al Congreso por elección popular, vinculándose en el quehacer político de manera inédita en el país.

Simultáneamente en otros países como México, en 1651 nacía sor Juana Inés de la Cruz, quien fuera una de las precursoras de la educación femenina. En Argentina en 1830 aparecía el primer periódico de mujeres titulado La Argentina para difundir los derechos femeninos. En Venezuela, Juana Rodríguez en 1813 organizaba un ejército de mujeres a favor de la causa de la independencia. En 1914 en Perú, María Alvarado fundaba la primera agrupación femenina de la época, llamada Evolución Femenina. O en Bolivia se creaba la Alianza de Liberación de la Mujer Americana, bajo el liderazgo de Yolanda Bedregal en 1959 [2].

Los acontecimientos mencionados forjados por el activismo femenino, si bien dieron paso a la integración de la perspectiva de género en las legislaciones, y marcaron el inicio en la implementación de mecanismos nacionales para garantizar la igualdad de acceso y participación equitativa ciudadana, aún visibilizan tensiones y procesos dispares en torno a las relaciones de género. Pues vemos que como sociedad se sigue transitado sobre las bases de una construcción social y cultural desigual, que con cifras violentas y preocupantes continúa desdibujando espacios femeninos y masculinos dominados por el poder, la opresión y los privilegios.

De allí la importancia de hacer en este momento un repaso de la normativa legal creada alrededor de la lucha iniciada por las mujeres previamente apuntadas y de otras menos visibles, para conocer los alcances que promueven, sus objetivos y los mecanismos que utilizan para cambiar la vida de las mujeres y en la práctica garantizar sus derechos.

\section{II.DESARROLLO}

El género es una construcción cultural y social forjada con base en las relaciones sociales, políticas, educativas, y culturales [3]. Las mismas que no son fijas y pueden variar, siempre y cuando no se confunda que 
estas responden a un conjunto de características construidas culturalmente y que no son de orden biológico, como se suele pensar. Porque el género a diferencia del sexo, como lo sostiene [4] viene determinado por la naturaleza, y es una construcción natural, con la que se nace.

Los estudios de género han demostrado en los últimos siglos que no se puede hablar aisladamente de un concepto que es polisémico y multidisciplinar [5], [6], pues este aborda vastas dimensiones y aristas de la sociedad. De ahí que propongamos repasar desde una mirada general relacionada con el papel que ejercen los organismos internacionales, hacia una local, vinculada con el estado, el diseño de políticas para mitigar las brechas de desigualdad teniendo como base el Buen Vivir.

\section{A.Género, una mirada desde los ODS}

El análisis está pensado desde una categoría general que comprende la revisión de los Objetivos de Desarrollo Sostenible [7], en adelante ODS, como una dimensión global que plantea la necesidad de priorizar el papel de la mujer y de todas las personas en desigualdad de oportunidades, para construir una sociedad que camina hacia el desarrollo sostenible. La declaración de [7] señala que los 17 objetivos promueven una educación ligada con la sostenibilidad, el respeto por los derechos humanos, la igualdad de género, el fomenta de la vida en paz y no violenta, la necesidad de vivir como ciudadanos del mundo sin las diferencias impuestas por las fronteras y otras formas de segregación y la cultura del desarrollo sostenible.

Este instrumento global es el que direcciona a partir de su planteamiento las agendas mundiales y temas emergentes en materia social, económica, educativa, cultural, pero sobre todo es la que incide en muchas de las políticas legislativas a nivel estatal en Ecuador. Sus presupuestos se reflejan claramente en el conjunto de leyes, decretos, planes o programas gubernamentales y en el modelo de sociedad que se pensó en la constitución de la república del 2008. Los preceptos de esta carta magna se desprenden en gran medida de las propuestas señaladas por la ONU para efectos de un trabajo articulado con los países del mundo.

Vale resaltar que el grado de armonización de esta propuesta mundial depende de las prioridades políticas, los arreglos institucionales y las capacidades técnicas, humanas y financieras que cada país tenga, además de la capacidad de inversión para los ámbitos de la salud, educación y otras áreas afines. Para el caso de Ecuador, la legislación está íntimamente ligada a nivel argumentativo con los principios consagrados que se recogen en el instrumento internacional propuesto por [7] pues rea- firma el compromiso por el derecho a la igualdad y a la no discriminación en todas sus formas y ámbitos.

Aunque a través de los 17 objetivos, inferimos la capacidad que tienen para concertar los insumos legislativos en el territorio, y la importancia que se cumplan dichas metas para que mujeres y colectivos, víctimas de discriminación, violencia y segregación, puedan acceder en igualdad de oportunidades de estudio, trabajo y a una vida autónoma y plena. Sin embargo, cabe mencionar que por el alcance especifico en torno al género, exploramos únicamente dos objetivos (5 y 10), puesto que inciden directamente en las arenas del género, sus convergencias, dificultades y barreras.

\section{B.El género un dispositivo de poder}

Para [8] y [9] al igual que sus predecesores [10], [11] el poder y las relaciones simbólicas que se construyen alrededor de las relaciones de género mantienen un aparente orden social, a través del ejercicio predominante del poder masculino, en todos los niveles que este opera. Y con frecuencia ese poder está asociado a un poder estatal, representado por la figura del hombre y no de la mujer.

En ese sentido, considerando el poder que tiene el Estado en la estructuración social, creemos que la práctica de las normas ya en la esfera de las relaciones sociales es sólo una de las diferentes partes que conforman el entramado sociocultural. Y, más bien debemos acudir a sus orígenes para conocer qué derechos, qué leyes y qué obligaciones tienen los gobiernos y las ciudadanías para construir una mejor sociedad. Esa postura abre la posibilidad de comprender si ese marco normativo es suficiente, coherente y si responde a las necesidades poblacionales.

A nivel gubernamental, el género se constituye en un dispositivo que organiza el sentido social, ya sea para hacer ejercicio de un poder dominante o transgredir las estructuras de opresión. Esa dualidad denota en el Ecuador desde inicios de la vida republicana, cuando la legislación negaba a la mujer el derecho al voto porque consideraba que no estaba en capacidad de ejercerlo [12], y cuando al mismo tiempo, la mujer representada por Matilde Hidalgo de Procel, luchaba por una legalidad ineludible del ser humano, "el derecho a tener derecho" [13].

De esa forma podemos percibir, cómo el género es una de las referencias recurrentes a través de las cuales el poder político ha sido concebido y legitimado [8]. En su nombre se han fomentado desigualdades que colocan a las mujeres en realidades y circunstancias menos privilegiadas que las de los hombres. Acudir al origen de esas determinaciones sociales cobra particular signi- 
ficado para comprender en qué se basan los gobiernos para establecer dicha normativa, porque como nos dice [8] la política no puede desvincularse del género, de la familia y de la sexualidad pues estos son sistemas que se relacionan unos con los otros que están articulados sinérgicamente en la esfera social.

Compartimos con [14] respecto a que cuando existe algún sujeto de género, es obligatorio hacer análisis de las sociedades desde la mirada de género. Por tanto, este debe ser analizado en sus amplias dimensiones y no como una categoría circunstancial, puesto que su rol es múltiple y activo en las distintas esferas de la sociedad. Como lo afirma esta autora, abordarlo desde su dimensionalidad nos permite abrir los horizontes de análisis desde lo social, económico, político, educativo, religioso, y desde luego desde su marco legislativo, que es en aquello que se centra este estudio.

\section{C.El género y su relación con la política del buen vi- vir en América Latina}

En América Latina, se vienen debatiendo e incorporando propuestas que reconocen los derechos de los pueblos y nacionalidades andinos a través de mecanismos normativos y narrativos centrados en el Buen Vivir. Bolivia comienza esta propuesta y contempla en su constitución el Vivir Bien [15] en Ecuador se promulga el Buen Vivir en la Constitución [16] y en Perú se enfatiza en torno a una Buena Manera de Vivir [17]. Todas como propuestas asociadas para lograr mejores condiciones de vida. En Ecuador el buen vivir es un principio constitucional basado en el "Sumak Kawsay" que recoge una visión del mundo centrada en el ser humano como parte de un entorno natural y social [18]. Esta perspectiva transversal y presente en la constitución de la República del año 2008 representa un conjunto de derechos individuales, colectivos y de naturaleza, de los cuales se derivan otros derechos [19], entre ellos los de libertad de género o educación.

En ese sentido, el máximo instrumento legal, la carta magna señala en el capítulo sexto que el estado formulará y ejecutará políticas para alcanzar la igualdad entre mujeres y hombres, a través de mecanismos especializados de acuerdo con la ley, e incorporará el enfoque de género en planes y programas, brindando asistencia técnica para su obligatoria aplicación [20].

La mejora de las condiciones de vida de ciudadanos de los países que han incorporado políticas tendientes a lograr estos objetivos, necesariamente están asociadas en aspectos como la igualdad de género y la posibilidad de tener oportunidades sin distingo de ningún tipo.

\section{III.METODOLOGÍA}

El estudio realiza una revisión documental y sistemática de campo, sobre la legislación ecuatoriana en materia de género, haciendo un preámbulo de los objetivos de Desarrollo Sostenible propuestos por la ONU en el 2015.

Según [21], el método documental permite explicitar un argumento de sentido que explica y totaliza una cierta visión práctica y con significado, cuyo orden ofrece la posibilidad de estructurar una manera de percibir el fenómeno, crear significados holísticos y que vaya más allá de lo real y tenga impacto en el contexto social. En ese aspecto, el resultado del análisis es el producto de un trabajo de acopio y revisión de documentos provenientes de la legislación del Estado ecuatoriano referida a género.

Para tal fin se llevó a cabo la búsqueda de los principales estamentos legales a nivel nacional para encontrar cuales son las leyes, normas, principios u orientaciones que rigen los temas de género como política pública en las últimas dos décadas, caracterizadas por un proceso de transformación social liderada por el modelo del socialismo del siglo XXI.

La búsqueda de la documentación tuvo como axioma articulador la variable "género" la misma que fue revisada bajo criterios específicos tanto en la información proveniente de organismos estatales a cargo de proteger y garantizar los derechos ciudadanos desde políticas relacionadas al enfoque de género (Asamblea Constituyente del Ecuador, Organismos Judiciales, Defensoría del Pueblo, INEC, Senplades, otros). Y, por otro lado, de información derivada de la literatura científica en torno a los estudios de género, legislación, violencia sexual y derechos humanos.

Una vez seleccionados deductivamente los documentos de interés, la sistematización develó cuatro categorías principales:

1.Objetivos de Desarrollo Sostenible [7].

2.Constitución del Ecuador [20].

3.Cuerpo Legal Ecuatoriano (13 instrumentos jurídicos entre leyes y códigos).

4.Planes y Proyectos gubernamentales.

Acorde a lo señalado por [22], este método documental se sirve de los libros y documentos como principales fuentes de información. Y son estos los medios más utilizados para la transmisión de conocimientos, ya sea de hechos históricos del pasado o de normativas estatales.

En consecuencia, los libros y documentos que analizamos fueron clasificados y etiquetados para una mejor 
identificación del descriptor "género", el cual se aplicó en la mayoría de los casos para identificar los estamentos de interés para la investigación, no así en lo que compete a la revisión de los ODS y del cuerpo legal.

Al respecto de la primera categoría, el trabajo deductivo se efectuó revisando los 17 ODS, e identificando aquellos que estaban relacionados con género, mujeres y desigualdad social. En ese caso, no se aplicó la búsqueda con el descriptor. En el segundo caso, en la Constitución de la República, se determinó por medio de un buscador con el descriptor, revisando los títulos, capítulos, secciones y artículos que incluían la palabra "género" para sustentar sus principios. Además, se hizo una lectura selectiva para identificar aspectos que, sin llevar la palabra género pudiese referenciar el objeto de estudio. En el tercer caso, la información fue obtenida del Atlas de Género del Ecuador [1] el cual tiene una agrupación previa de la legislación nacional en asuntos de género ordenada cronológicamente y detalla lo que contiene cada una. Finalmente, en cuanto a los planes y proyectos gubernamentales, se aplicó también el uso del descriptor, para identificar los apartados y describirlos posteriormente en una categoría general. Se revisaron documentos provenientes de las siguientes entidades a nivel nacional y regional: ODS, Constituyente del Ecuador, Defensoría del Pueblo y Planes y programas gubernamentales.

\section{IV.RESULTADOS}

\section{A.El género y su importancia colectiva}

La importancia y el fin vinculante del planteamiento de la agenda 2030 para el Desarrollo Sostenible propuesta por los estados Miembros en la Asamblea General de las Naciones Unidas [7] tiene como meta alcanzar una sociedad más justa social y económicamente a nivel global. En ese orden los objetivos planteados como mecanismos para alcanzar el fin central, proponen una conexión transdiciplinaria de metas en cuanto a: cero pobreza, hambre cero, salud y bienestar, calidad educativa, igualdad de género, agua limpia y saneamiento, energía asequible y no contaminante, trabajo decente y crecimiento económico, industria, innovación e infraestructura, comunidades sostenibles, producción y consumo responsable, acción por el clima, vida submarina, vida de ecosistemas terrestres, paz, justicia e instituciones sólidas, alianzas para lograr los objetivos.

Si bien estos objetivos responden a transformaciones sociales, ambientales, culturales y económicas, podemos destacar que nos interesan dos para este estudio, el ODS 5 por plantear la igualdad de género y empoderar a todas las mujeres y niñas; y el ODS10 por proponer la reducción de las desigualdades.

El ODS 5 reconoce la centralidad de la igualdad de género y el empoderamiento de las mujeres para transitar hacia patrones de desarrollo sostenible, al tiempo que afirma que cada país dispone de diferentes enfoques, visiones de futuro, modelos e instrumentos para lograr el desarrollo [23], por ende, se convierte en una de las propuestas centrales para lograr el objetivo común al 2030, una sociedad más justa y con igualdad de oportunidades.

La relevancia que se da al tema de género, no como pulso argumentativo o discursivo [8] sino como una política pública global, que recupera los derechos de las mujeres y las niñas para ser tratadas sin ser discriminadas por su género o sexo, ocurre en un momento fundamental, cuando se visibiliza la importancia que tiene en todas las esferas y niveles para alcanzar una igualdad que no se ha logrado, dado el sitial que ocupa en la sociedad. En los ámbitos laborales, familiares, escolares y sociales, la figura femenina ha permanecido a cargo del cuidado de la familia. Por esa razón, para autores como [24], [25] la prioridad del trabajo y de la imagen de la mujer no ha cambiado, pues su papel sigue concibiéndose desde un rol secundario, una ciudadana de segunda clase, y como protagonista del espacio privado, el cual no es considerado [26] relevante en la esfera social.

Posteriormente, el ODS 10 aborda los temas de desigualdad, justicia social, discriminación o pobreza. Se enfoca en la reducción de las brechas de desigualdad por cuestiones económicas, sociales, culturales, religiosas, políticas y educativas. En ese sentido, la mujer como sujeto permea en cada uno de esos elementos constitutivos que la conducen a remarcar las asimetrías en diversos ámbitos, por su condición femenina. No obstante, lo masculino también cruza por esas diferencias, pero como lo señala [27] en circunstancias y escenarios diferentes, no en mejores condiciones, pero si diferentes.

Ya a nivel nacional, en función de esas directrices globales que repasamos, encontramos que Ecuador cuenta con instrumentos legales que amparan la igualdad de género como elemento fundamental en la defensa de los derechos de las mujeres y de las paridades relacionadas con la diferencia de género [1]. Sin duda, el principal instrumento normativo lo representa la Constitución de la República del año 2008.

\section{B.Constitución de la República del Ecuador 2008}

En Ecuador, [20] es el documento legal principal, porque recoge en su legislación no sólo principios de igualdad de género, sino de derechos fundamentales, y lineamientos básicos para orientar la normativa en ma- 
teria de género y la política pública nivel nacional.

Tabla 1. Secciones con enfoque de género en la Constitución de la República del Ecuador.

\begin{tabular}{|c|c|c|c|}
\hline Título & Capítulo & Sección & $\begin{array}{c}\mathbf{N}^{\circ} \\
\text { Artículo }\end{array}$ \\
\hline \multirow{14}{*}{$\begin{array}{c}\text { II } \\
\text { Derecho } \\
\text { s } \\
\end{array}$} & Primero & & 11 \\
\hline & & & \\
\hline & & & \\
\hline & $\begin{array}{l}\text { Segundo: Derechos } \\
\text { del Buen Vivir }\end{array}$ & $\begin{array}{l}\text { Quinta: } \\
\text { Educación }\end{array}$ & 27 \\
\hline & & Séptima: Salud & 32 \\
\hline & $\begin{array}{l}\text { Tercero: Derechos } \\
\text { de las personas y } \\
\text { grupos de atención } \\
\text { prioritaria }\end{array}$ & $\begin{array}{c}\text { Primera: adultas } \\
\text { y adultas } \\
\text { mayores }\end{array}$ & 38 \\
\hline & & Quinta & 45 \\
\hline & $\begin{array}{l}\text { Quinto: Derechos } \\
\text { de participación }\end{array}$ & & 61 \\
\hline & $\begin{array}{c}\text { Sexto: Derechos de } \\
\text { libertad }\end{array}$ & & 70 \\
\hline & $\begin{array}{l}\text { Octavo: Derechos } \\
\text { de protección }\end{array}$ & & 77 \\
\hline & $\begin{array}{c}\text { Noveno: } \\
\text { Responsabilidades }\end{array}$ & & 83 \\
\hline & $\begin{array}{l}\text { Segundo: Función } \\
\text { legislativa }\end{array}$ & $\begin{array}{c}\text { Segunda: } \\
\text { consejos } \\
\text { nacionales de } \\
\text { igualdad }\end{array}$ & 156 \\
\hline & & $\begin{array}{c}\text { Tercera: Fuerzas } \\
\text { Armadas y } \\
\text { Policía }\end{array}$ & 160 \\
\hline & $\begin{array}{l}\text { Sexto: Función } \\
\text { electoral }\end{array}$ & & 127 \\
\hline $\begin{array}{c}\text { Título } \\
\text { VII }\end{array}$ & $\begin{array}{c}\text { Primero: Inclusión } \\
\text { y equidad }\end{array}$ & Segunda: Salud & 358 \\
\hline $\begin{array}{l}\text { Régimen } \\
\text { del Buen } \\
\text { Vivir }\end{array}$ & & & \\
\hline
\end{tabular}

Tal como se muestra en los títulos II (sobre Derechos) y VII (Régimen del Buen Vivir) la Constitución de la República [20], recoge varios capítulos, secciones y artículos que resultan sustanciales para el análisis, puesto que entrelazan la perspectiva de género en sus estamentos legales de la mano de enfoques que valoran la diversidad cultural y la paridad entre personas sin distinción de sexo, etnia, religión o cualquier otra diferencia que suponga conflicto, sino que más bien las propone como fuentes de enriquecimiento para vivir armónicamente en una sociedad plural que cumple deberes y respeta los derechos de los demás.

Por ejemplo, ante la discriminación por etnia, nacimiento, género, edad sexo, identidad cultural, estado civil, idioma o religión, el documento constitucional na- cional ampara en el capítulo I, artículo 11 que todas las personas son iguales y gozan de los mismos derechos, deberes y oportunidades. En un país como Ecuador matizado por la pluriculturalidad y la diversidad, este tipo de contemplaciones legales constituye un avance necesario para alcanzar sociedades más justas y prácticas menos discriminadoras.

Más adelante plantea el derecho a la educación como un componente esencial para el Buen Vivir, dado que a través de esta se fomenta el desarrollo de las potencialidades humanas, y se garantiza la igualdad de oportunidades para todas las personas. Cabe señalar que el Buen Vivir es un eje esencial para la educación, pues contempla la formación de futuros ciudadanos con valores y conocimientos que puedan construir una mejor 
sociedad.

Varios capítulos y secciones sobre temas de inclusión y equidad se organizan en torno a la salud, y para ello promueven la creación y sostenibilidad de un sistema sanitario con característica inclusivas, interculturales, solidarias, con enfoque de género y generacional. Tienen como objetivo establecer que no haya distinción en las prestaciones de servicios a los usuarios, que por cuestiones de género no se limite la atención, ni menos por cuestiones étnicas. Y que en ese amparo la ciudadanía goce de una vida saludable e integral.

También se contemplan políticas y programas de atención hacia personas de la tercera edad en zonas urbanas y rurales, priorizando la equidad de género, etnia, cultura y diferencias sociales. De ahí que la diversidad cultural y la distribución poblacional no sean un impedimento para ejercer acciones que favorezcan a la ciudadanía sin importar el entorno geográfico en donde habitan.

Otro fundamento visible es la erradicación de la violencia de género y la discriminación. Y por tanto los organismos de control de la comunicación a nivel nacional están articulados para prevenir que los medios repliquen noticias que propicien prácticas estereotipadas.

Vemos además que tantos los derechos de participación, libertad y de protección están presente en la carta magno, garantizando la protección eficaz, equitativa, plural y en igualdad de condiciones entre mujeres y hombres. La política pública ha logrado calar en todas las dependencias estatales (ministerios, institutos, programas) para brindar asistencia técnica y aplicar los principios de obligatoriedad en esos campos. En ese sentido, las víctimas de violencia, discriminación y acoso están protegidas y pueden solicitar la ayuda del estado para la remediación de daños psicológicos y ante posibles situaciones de riesgo y vulnerabilidad.

En cuanto a la función legislativa se destaca que los consejos nacionales de igualdad aseguran los derechos consagrados en la constitución y en los instrumentos internacionales de derechos humanos. Tal como se estipula estos organismos tienen como atribuciones en la formulación, transversalización observancia, seguimiento y evaluación de las políticas públicas relacionadas con las temáticas de género, étnicas, generacionales e interculturales.

Cabe destacar que la observancia y los principios de paridad de género y acceso a oportunidad sin distinción por la condición femenina o masculina, también están establecidas en las políticas que rigen organismos como las Fuerzas Armadas y la Policía Nacional. Prueba de ello es que en los últimos años la cuota de programas para acceder a las carreras militares y de la policía no distinguen cuestiones de género y promueven la inserción en sus filas de mujeres.

De lado de la función electoral, como reza la constitución también está visible el enfoque de género, al proponer lineamientos jurídicos para abordarlo en las políticas sobre la base de los principios del Buen Vivir. Así tenemos por ejemplo una distribución par en los cargos ministeriales, en los que los dos últimos gobiernos (2007-2017 / 2017-2021) han posicionado tanto a mujeres y hombres calificados. Esos cambios sustanciales también son visibles en los curules que ocupan las mujeres asambleístas a nivel nacional. Aunque, no obstante, pese a que ha habido avances en cuanto a una mayor participación de la mujer en temas políticos y electorales.

\section{C.Legislación Nacional}

En el Ecuador tienen efecto otros cuerpos legales que se encuentran bajo el amparo de la Defensoría del Pueblo en un caso, y en otros modelos más orientativos que rigen su política pública acorde a los principios obligatorios de la Constitución y de ejes y políticas específicas.

Es por ello que revisamos las leyes que, a decir por la Defensoría del Pueblo, son claves para abordar el enfoque de género desde las bases constitucionales, y también un marco normativo derivado de la constitución, traducido en planes, agendas y programas de índole social.

La Defensoría del Pueblo es un órgano de derecho público con jurisdicción nacional, personalidad jurídica y autonomía administrativa y financiera que se plantea como un espacio cercano a la población y capaz de viabilizar con mayor rapidez las demandas sociales. Por su naturaleza es la Institución Nacional de Derechos Humanos que promueve y protege los derechos de personas, comunidades, pueblos, nacionalidades y colectivos que habitan en el país; en el exterior; y los derechos de la naturaleza, para propiciar la vida digna y el buen vivir [1]. Y dada la realidad que vive el país y las brechas étnicas, culturales, religiosas y de género, recoge permanentemente denuncias relacionadas a esos asuntos.

Este organismo resalta en materia de género que la legislación nacional ha desarrollado un vasto cuerpo legal centrado en erradicar la violencia, la protección de la mujer, de la familia y la discriminación por el hecho de ser mujer. De esa forma, teniendo presente que las cifras de femicidios en Ecuador son cada vez mayores, y que solo en el año 2020 una centena de mujeres murieron por su condición femenina, y que estos crímenes fueron ejecutados por miembros masculinos dentro del 
círculo familiar; el Estado tiene la obligación de formular reformas y leyes que atenúen el incremento de cualquier forma de vehemencia. Por tanto, los estamentos legales articulados para cambiar una tónica social que se traduce en violencia y crimen, proponen mecanismos que están orientados en combatir y erradicar la violencia de género [28].

Otras leyes y códigos en esa misma línea están relacionados con la protección de otros grupos poblacionales vulnerables: niñez y adolescencia, dado que dentro de sus márgenes son repetitivas también prácticas que violentan sus derechos y los colocan en un peligro inminente. Así, por ejemplo, lo expresan [29] y [40] que representan en este punto, los cuerpos que garantizan de manera directa la seguridad y la vida de mujeres, niñas, niños y adolescentes.

De su parte a nivel laboral, el [30] contiene reformas y legisla en pro de los beneficios de los trabajadores, y ha regulado desde hacía varias décadas acciones que favorecen e integran la perspectiva de género. Tal es el caso de las licencias por maternidad, paternidad, los derechos de las madres durante los períodos de lactancia, y la defensión de la mujer antes despidos intempestivos.

En materia educativa, como lo señala la constitución, se articulan esfuerzos y políticas no solo para que la población tenga derecho a una educación participativa y democrática, sino que esta atraviese el foco intercultural y la perspectiva de género para garantizar el logro de los objetivos propuestos como sociedad y estado. Así encontramos la [36], misma que representa un hito para la historia del país a contener principios constitucionales que protegen no solo al ser humano sino al contexto que lo rodea. A la par de este principio, la [37] propone la libertad de expresión sin condiciones de género, prohibiendo la discriminación, la estereotipación y las prácticas machistas y sexistas en los medios de comunicación. Esta ley concibe a la comunicación como un derecho humano nacional, que debe velar por el bienestar y la calidad de contenidos que recibe la ciudadanía.

En el plano jurídico y penal, tanto el [38] como el [39] caminan de la mano, por un lado garantizando la designación y funciones de los miembros que velan por la igualdad de género, y por otro determinan normas jurídicas, en el caso del código penal, de carácter punitivo estableciendo delitos y penas para quienes infrinjan la ley y cometan acciones que violentes los derechos de las personas, pero particular-mente de mujeres en la sociedad ecuatoriana.

Alrededor de la función legislativa, de control social y fines electorales, podemos evidenciar por lo que delinea la Defensoría del Pueblo, que existen también herramientas precisas para garantizar la participación y permanencia de mujeres y hombres en igualdad de condiciones y con las mismas oportunidades. Tanto las figuras legales [31], [32] y [33] reflejan un imaginario colectivo que promueve principios de igualdad y participación en la vida pública y en contiendas políticas y electorales, y aclaran también cómo operan los lineamientos de sanción para quienes incumplan los deberes circundantes al género.

Finalmente, figuras como [34] y [35] afines con la organización territorial y la planificación de las finanzas, muestran una transversalización requerida para incorporar también una mirada justas y equitativo. Sus alcances plantean la inserción de enfoques de género, étnico culturales, generacionales y de movilidad.

Con esta revisión parcial del corpus normativo de género, pese a que Ecuador plantea gestiona un sistema penal, constitucional y jurídico a todas luces cuenta con los mecanismos argumentativos para hacer cumplir la ley y proteger a una población históricamente agredida emocional, psicología y físicamente, no se evidencia un cambio social integral, puesto que las cifras de violencia siguen incrementándose diariamente en el país.

Respecto a los planes y programas estatales en materia de género, estos constituyen un conjunto de leyes y códigos que suman instrumentos que garantizan los derechos ciudadanos y objetivos comunes para el buen vivir y promueven un trabajo sostenido en todos los niveles sociales para que la legislación antes señalada encuentre mecanismos que la sostenga.

Acorde al Atlas de Género [1] varios de estos planes y programas que contienen en sus estamentos dispositivos relacionados con la equidad de género son cinco: Plan Nacional de Erradicación de la Violencia Intrafamiliar y de Género, hacia la Niñez, Adolescencia y Mujeres (2007) [41]; Plan Nacional de erradicación de Delitos Sexuales en el Ámbito Educativo (2008) [42]; Agenda Nacional de las Mujeres y la Igualdad de Género (2012-2017) [43]; Plan Toda Una Vida (2017-2021) [16].

Estas propuestas hacen posible una política pública que no puede sostenerse aislada, sino que requiere de otros elementos, dependencias y posibilidades, mayores instrumentos que coadyuven a llevar a la práctica la ley.

En el primer caso, ante las cifras de abuso sexual e índices de violencia intrafamiliar atentatorias en contra de mujeres, niñas (os), adolescentes por parte de su padres, parejas o adultos con mayor poder, se dispone afortunadamente de un aparato legal [41] que permite visibilizar los delitos sexuales ante la vulneración de derechos de niñas, niños y adolescentes. El plan se fundamenta en una propuesta de transformación estructural que afecta a miles de familia y que busca cambiar la 
sociedad y su pensamiento de raíz.

En el segundo caso, se promueve a partir de la [42], un trabajo alrededor de la erradicación de delitos sexuales en el sector educativo, lo que hace preciso la incorporación de ejes transversales en torno a derechos humanos, perspectiva de género, interculturalidad, inclusión, equidad y justicia social, con el fin de contribuir a ese cambio estructural social, desde pensamientos y acciones que garanticen la sana convivencia y el respeto por la otredad.

En el tercer punto, la gestión pública propone un eje especializado en resolver y atender los problemas de la mujer, que ayude a superar las brechas de desigualdad de género. Pero que además visibilice el mapa de inequidad y circunstancial por el que atraviesa la categoría femenina y colectivos como el LGTBI (lesbianas, gays, transgénero, transexuales travestis e intersexuales) en situación de desventaja frente a otros colectivos sociales. Advierte al mismo tiempo las brechas de inequidad y desigualdad que afrontan las mujeres y personas LGBTI, para poder abordarlas y mediar situaciones que supongan agravios en su contra. La propuesta de [28] y esta agenda han logrado importantes avances. Un caso que podemos citar es la aprobación del matrimonio igualitario en 2019, el cual respalda la unión entre personas del mismo sexo.

Por último, la propuesta de [16] sirve como una guía orientativa para promover la filosofía del Buen Vivir y avanzar hacia una sociedad más justa, equitativa y solidaria. Este instrumento de la política pública, sustentado en el antes denominado Plan Nacional de Desarrollo 2017-2021, presenta varios mecanismos y propuestas para garantizar mejores condiciones a personas en situación de desventaja, durante las diferentes estas de la vida. De esa manera, busca fortalecer las capacidades y la generación de oportunidades mediante varios axiomas relacionados con el cuidado de la primera infancia, el fortalecimiento y desarrollo para las (os) jóvenes, el acompañamiento a personas adultas y la eliminación de barreras desiguales. Los subprogramas que se desprenden de este plan son la Misión Ternura, Misión Impulso Joven, Misión Mis Mejores Años, Misión Mujer, Misión Casa para Todos, Misión Manuelas y Misión Menos Pobreza más Desarrollo. Cabe mencionar que en el marco de esos lineamientos se benefician miles de ecuatorianas (os) que viven en la extrema pobreza.

Por sus alcances estas propuestas tienen en común modificar las condiciones estructurales de desigualdad y pobreza en Ecuador. En ese margen la legislación y priorización por los temas de mujeres, niños, adolescentes y colectivos LGTBI exponen la emergencia de fortalecer políticas y propiciar cambios y acciones pro- fundas en todos los niveles donde permea la pobreza y la desigualdad.

\section{V.CONCLUSIONES}

Aunque con las propuestas asentadas por la Asamblea Nacional en la reforma constitucional del 2008 se dio un giro a la narrativa constitucional en materia de derechos, entre estos la libertad de género, doce años después siguen permeando las brechas de discriminación e inequidad que afectan a las mujeres y a otros colectivos de género en condición de vulnerabilidad. Los problemas sociales siguen estancados sin avances o soluciones concretas, a pesar de contar con instrumentos legales, que deben ser respetados y de cumplimiento obligatorio. La gran ola neoliberalista patriarcal que no concibe políticas de transformación social en beneficio de las personas sin importar su género, clase o social o etnia, y continúa invisibilizando temas tan emergentes.

Las reformas a las leyes deberían ser la respuesta del estado a los dilemas sociales que vive el país, y deben ser analizadas desde la lógica de pensamientos plurales. Los encargados de la legislación y sus transformación o propuestas deben actuar desde una postura que mire al ser humano como un sujeto de derecho, con la posibilidad de gozar de una vida libre de violencia, opresión y discriminación.

Tampoco la Agenda al 2030 y los Objetivos de Desarrollo Sostenible han logrado conquistas tangibles en torno al respeto y cumplimiento a los derechos por la equidad y justicia social en materia de género. Si bien, tanto estos como la legislación nacional, están armónicamente diseñados y entrelazados desde la teoría, queda en evidencia que el género es un problema estructural de nuestras sociedades y que el Estado, como ente garantista no debe contar únicamente con una normativa para el efecto, sino que debe articular, desde las bases y desde adentro, políticas públicas que sostengan un proyecto de transformación social a largo plazo, con la participación colectiva porque es un asunto que nos convoca y afecta a todos.

Respecto a la aplicación de políticas como la del Buen Vivir, surgiendo de países latinoamericanos representan una fortaleza de la región en la búsqueda de condiciones de género justas y ello contribuye a que paulatinamente se vaya cerrando la brecha que en esta materia existe entre países de otros continentes, que han logrado mejoras significativas respecto a la igualdad de géneros y los países latinoamericano, cuyas luchas comenzaron no sólo más tarde sino con menos fuerza que aquellos.

Sin embargo, la aplicación de estas políticas limpiamente, es decir, sin que se inmiscuyan intereses políti- 
cos, religiosos, económicos, etc. es el reto que los Estados deben enfrentar, desafío este de vital importancia y de difícil materialización, sobre todo cuando las realidades de nuestros países están plagadas de necesidades básicas, donde lo urgente suele dejar a los importante en un segundo plano.

Por otra parte, hay pocos estudios que analicen la legislación ecuatoriana desde el enfoque de género y que visibilicen la necesidad de políticas integradoras para el bien común de la sociedad. Los consejos de participación ciudadana, democracia e igualdad deben hacer eco de una voz colectiva que reconfigure el estado laxo de los estudios de género, abriendo horizontes que coloquen al ser humano por encima de sus diferencias y de sus creencias.

Finalmente, la educación ciudadana en materia de género es un importante pilar en el que se debe sustentar el cambio legislativo pues, aunque esté plasmada la equidad de género en instrumentos legales, mientras los ciudadanos no se apropien en conjunto de lo que realmente implica aspectos como la equidad de género, ninguna ley podrá lograr su objetivo.

\section{REFERENCIAS}

[1]C. Valle, Atlas de Género, Quito: Instituto Ecuatoriano de Estadísticas y Censos, 2018.

[2]L. M. Martínez y T. Escapa, Guía de formación para la participación social y política de las mujeres: manual de la alumna, Extremadura: Instituto de la mujer, 2009. [3]J. Bluter, Gender trouble, feminist theory, and psychoanalytic discourse. Feminism/ post-modernism, California: Siglo XXI, 1990.

[4]S. Castellví, "Estereotipos jurídicos y género: análisis conceptual, jurídico y político-moral del impacto de los estereotipos de género" M.S. thesis, Universidad de Barcelona, España, 2018.

[5]S. Federici, Caliban y la Bruja. Editorial Traficante de Sueños, Madrid: Traficante de sueños, 2004

[6]B. Risman, "Gender as a social structure: Theory wrestling with activism,» Gerder \& Society, vol. 18, $\mathrm{n}^{\circ}$ 4, pp. 429-450, 2004.

[7]ONU, «Organización de Naciones Unidas,» 25 septiembre 2015. [En línea]. Available: https://www. un.org/sustainabledevelopment/es/2015. [Último acceso: 18 agosto 2020].

[8]J. Scott, El género, una categoría útil para el análisis del, Oxford: Oxford Press, 1986.

[9]R. Connell, Gender and power: Society, the person and sexual politics, John Wiley \& Sons., 2013.

[10]M. Foucault, Estrategias de poder, Argentina: Ediciones Paidós Ibericas S.A. Colección obras especiales, 1999.
[11]P. Bourdieu, " El espacio social y la génesis de las" clases",» Sociología y cultura, vol. 7, n ${ }^{\circ} 3$, pp. 27 55,1989 .

[12]A. Goetschel, Orígenes del feminismo en el Ecuador, Quito: FLACSO, 2006.

[13]H. Arendt, «Las perplejidades de los Derechos del Hombre,» Los orígenes del totalitarismo, Madrid, Alianza, 1987, pp. 412-427.

[14]M. Lagarde, «La multidimensionalidad de la categoría género y del feminismo.,» de Metodología para los estudios de Género, México, UNAM, 1996, pp. 4871.

[15]E. Gudynas y A. Acosta, «El buen vivir más allá del desarrollo,» Revista Quehacer, $n^{\circ}$ 181, pp. 70-83, 2011. [16]Senplades, Plan Toda una vida. Plan Nacional de Desarrollo (2017-2021), Quito: Secretaría Técnica Planifica Ecuador, 2017

[17]A. Quijano, Colonialidad del poder y subjetividad en América Latina, Buenos Aires: Clacso, 2015.

[18]Ministerio de Educación-Ecuador, «Educación para la democracia y el buen vivir,» Mineduc, S/F. [En línea].Available: https:/educacion.gob.ec/que-es-elbuen-vivir/. [Último acceso: 18 noviembre 2020].

[19]M. Villagómez \& R. Cuhna, « Buen vivir y educación para la práctica de la interculturalidad en el Ecuador. Otras prácticas pedagógicas necesarias,» Alteridad, vol. 9, $\mathrm{n}^{\circ}$ 1, pp. 35-42, 2014.

[20]Asamblea Nacional Constituyente, Constitución de la República de Ecuador, Montecristi, 2008.

[21]B. Hoyos, Un Modelo para Investigación Documental: Guía teórico práctica sobre construcción de Estados del Arte con importantes reflexiones sobre investigación, Medellín: Librería Señal Editora, 2000.

[22]A. Botero, «La metodología documental en la investigación jurídica: alcances y perspectivas,» Opinión jurídica, vol. 2, nº 4, pp. 109-116, 2003.

[23]CEPAL, «Pactos para la igualdad,» CEPAL, Buenos Aires, 2016.

[24]J. Lorber, «Gender inequality: Feminist theories and politics,» Roxburiy, Albany, 2001.

[25]A. Vásconez, Mujeres y protección social en Ecuador, Quito: MIES, 2014.

[26]N. Yuval-Davis, «Gender and Nation,» SAGE Journals, vol. 16, nº 4, pp. 621-632, 1997.

[27]D. De Dios-Vallejo, «Equidad de género y embarazo.,» Perinotalogía y reproducción humana., vol. $28, \mathrm{n}^{\circ}$ 2, pp. 71-78, 2014.

[28]Gobierno de Ecuador, Ley Contra la Violencia a la Mujer y la Familia-Ley 103, Quito, 1995

[29]Gobierno de Ecuador, Código de la Niñez y la Adolescencia. (97) publicado por la ley Nº101, Quito, 2003. [30]Ministerio de Relaciones Laborales, Código del 
Trabajo, Quito, 2005.

[31]Gobierno de Ecuador, Ley Orgánica del Consejo de Participación Ciudadana, Quito, 2009.

[32] Gobierno de Ecuador, Ley Orgánica Electoral. Organizaciones Políticas de la República del Ecuador, Código de la Democracia, Quito, 2009.

[33]Gobierno de Ecuador, Ley Orgánica de la Función Legislativa, Quito, 2009.

[34]Gobierno de Ecuador, Código Orgánico Organización Territorial Autonomía Descentralización, Quito, 2010.

[35]Gobierno de Ecuador, Código Orgánico de Planificación y Finanzas Públicas, Quito,2010.

[36] Asamblea Nacional de Ecuador, Ley Orgá-nica de Educación Intercultural, Quito, 2011.

[37]Asamblea Nacional de Ecuador, Ley Orgánica de Comunicación, Quito, 2013.

[38]Asamblea Nacional de Ecuador, Código Integral Penal, Quito, 2013.

[39]Asamblea Nacional de Ecuador, Ley Orgánica para la Igualdad. Ley Orgánica de los Consejos Nacionales para la Igualdad, Quito, 2014.

[40]Asamblea Nacional de Ecuador, Ley Orgánica Integral para Prevenir y Erradicar la Violencia Contra las Mujeres, Quito, 2018.

[41]Ministerio de Justicia, Plan Nacional de Erradicación de la Violencia Intrafamiliar y de Género, hacia la Niñez, Adolescencia y Mujeres., Quito, 2007.

[42]Ministerio de Inclusión, Plan Nacional de erradicación de Delitos Sexuales en el Ámbito Educativo, Quito, 2008 .

[43]Gobierno de Ecuador, Agenda Nacional de las Mujeres y la Igualdad de Género 2012-2017, Quito, 2012.

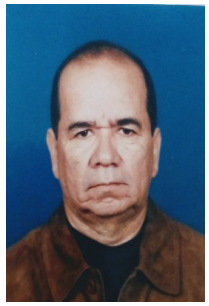

Humberto Castillo Quintero, Docente e investigador Universidad de Los Andes. Evaluación Educativa. Magister en Gerencia Educativa. UNET. Doctor en Filosofía y Cs. de la educación. Universidad Nacional de Educación a Distancia UNED (España).

\section{RESUMEN CURRICULAR}

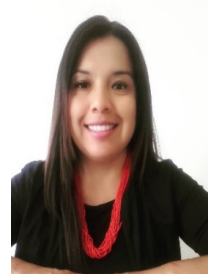

Fanny Tubay Zambrano, Docente e Investigadora en interculturalidad y estudios de género. Profesora de la Universidad Técnica de Manabí-Ecuador. Máster en Educación Intercultural y Doctora en Educación Universidad Nacional de Educación a Distancia UNED (España)

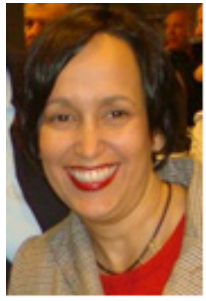

María Angélica Henríquez Coronel, Investigadora y Docente Universitaria. Doctora en Pedagogía (Universitat Rovira y Virgili, España), Magister en Informática Educativa (Universidad Simón Bolívar, Venezuela), Licenciada en Educación (Universidad Católica del Táchira). 